\title{
ATIVIDADES DIGITAIS: SEU USO PARA O DESENVOLVIMENTO DE HABILIDADES COGNITIVAS*
}

\author{
Cláudio Afonso Tiellet - UFSM/RS - tielletcab@yahoo.com.br \\ Gilse Antoninha. Morgental Falkembach - ULBRA/SM - gilsemf@terra.com.br \\ Nires Metilde Colleto - UNIFRA/RS - nires@unifra.br \\ Larisa Rosa dos Santos - UNIFRA/RS- lari.matematica@bol.com.br \\ Patric da Silva Ribeiro - UNIFRA/RS - patricribeiro@terra.com.br
}

RESUMO: O presente trabalho apresenta as atividades digitais que foram criadas, modeladas e implementadas, objetivando visualizar a importância dos jogos educativos digitais como recurso didático nos processos de aprendizagem e desenvolvimento do raciocínio lógico matemático e espacial. O trabalho focalizou a forma como se processa aprendizagem, a contribuição da informática para educação, o uso dos jogos digitais nas escolas e suas conseqüências no processo de ensino e aprendizagem. Os jogos educativos digitais tornam-se relevantes, tendo em vista que os alunos se envolvem emocionalmente, promovendo uma aprendizagem significativa. Foi realizado de forma integrada com o curso de Sistemas de Informação (UNIFRA) para o desenvolvimento do material digital e o curso de Matemática (UNIFRA) na criação e desenvolvimento das atividades.

Palavras-chave: processo de aprendizagem, jogos educacionais, ludicidade digital.

ABSTRACT: The present work presents the digital activities that had been created, shaped and implemented, aiming to visualize the importance of digital educational games as didactic resource in learning processes and in the development of the mathematical and spatial logical reasoning. The work focused the way that the learning is processed, the contribution of computer science for education, the use of digital games at schools and its consequences in the educational process and learning. The digital educational games become relevant, considering that the pupils get emotionally involved, promoting a significant learning. The project was realized integrating the graduation courses of Systems of Information (UNIFRA), developing the digital material, and Math (UNIFRA), creating and developing the activities.

Keywords: learning processes, digital educational games.

\section{INTRODUÇÃO}

A dificuldade dos alunos em Matemática é muito significativa e começa nos primeiros anos da vida infantil. Por meio da Informática na Educação sabe-se que o computador pode auxiliar e fazer com que o aluno se envolva no processo de aquisição do conhecimento. As tecnologias digitais, como instrumento mediador do processo de ensino e aprendizagem, tornam-se relevante, pois os alunos se envolvem emocionalmente com as atividades também chamadas de jogos educacionais e encontram significado para sua aprendizagem. $\mathrm{O}$ presente trabalho apresenta as atividades digitais que foram criadas, modeladas e foram implementadas para o desenvolvimento do raciocínio lógico matemático e espacial.

Os jogos educativos o atividades educativas digitais baseiam-se no interesse que as crianças têm em brincar e jogar. $\mathrm{O}$ jogo é uma importante ferramenta para o ensino e aprendizagem, pois na vida da criança o jogo ocupa o papel principal, conforme * Trabalho de Iniciação Cientifica PROBIC/UNIFRA.

Batlori(2004), "especialmente nos primeiros anos de vida, tudo é jogo e é por meio de jogos que a criança vai aprendendo muitas coisas". É por meio da brincadeira que a criança se desenvolve e sem perceber aprende diversos conceitos significativos para sua vida. As crianças brincam com dedicação, entusiasmo e seriedade. As crianças, investem no prazer lúdico, no desafio do momento, na alegria e até mesmo nos esforços sofridos para vencer os desafios de certos jogos. Jogando a criança, o jovem ou mesmo o adulto sempre aprende 
algo, sejam habilidades, valores ou atitudes, portanto, pode-se dizer que todo jogo ensina. Isso não significa que tudo que o jogo ensina é bom, é educativo. O jogo é lúdico. Toda a atividade que incorpora a ludicidade pode se tornar um recurso facilitador do processo de ensino e aprendizagem. Por meio da multimídia é possível trabalhar qualquer conteúdo de forma agradável e estimulante. As atividades digitais, entre elas, o jogo, se constituem em ferramentas que se bem utilizadas ensinam enquanto divertem.

A utilização do jogo como instrumento facilitador do processo de ensino e aprendizagem, exige que seus objetivos pedagógicos sejam bem claros, e que seja priorizada a qualidade. Para se obter bom resultado com jogos educativos é preciso um planejamento adequado com relação ao seu uso. O jogo educativo deve exibir o conteúdo com uma pedagogia implícita e seu design deve ser adequado às diferentes faixas etárias com telas agradáveis.

Tendo em vista a importância do jogo para o processo de ensino e aprendizagem e em especifico as dificuldades que os alunos encontram na disciplina de Matemática, sendo esta muito significativa, começando nos primeiros anos da vida infantil, é que foi elaborado o projeto com o objetivo de criar uma aplicação multimídia para o desenvolvimento do raciocínio lógico matemático e espacial.

Visando uma aprendizagem significativa foram criadas atividades digitais para $o$ desenvolvimento do raciocínio matemático, que possibilita a construção do conhecimento e não apenas a memorização e reprodução de técnicas de forma a estimular a capacidade de associação de idéias, desenvolver a agilidade do cálculo mental, melhorar o raciocínio abstrato, aprender a observar e perceber imagens,favorecer uma visão global, melhorar a capacidade de concentração e facilitar a capacidade de associação de conceitos.

\section{APRENDIZAGEM}

Um dos objetivos da Educação é a aprendizagem, ou seja, aprendizagem de bons hábitos, boas maneiras, de habilidades e fundamentalmente a aprendizagem de conteúdos que envolvem várias áreas do conhecimento, ou seja: conhecimentos científicos; saberes culturais; experiências vividas; valores formativos, morais e éticos.

Aprender, de acordo com Bordenave(1996), "é uma atividade que acontece no aluno e que é realizada por ele. As pessoas não podem aprender umas pelas outras." Deste modo, a aprendizagem é um processo integrado, qualitativo, não é um aumento quantitativo de conhecimentos, mas, de uma transformação das estruturas mentais da pessoa. Na escola, o agente da aprendizagem é o aluno e o professor é o facilitador deste processo.

$\mathrm{O}$ aluno é o agente de seu processo de aprendizagem e ela está ligada à diversas características individuais tais como: seu nível de motivação, sua maturidade sócioemocional, sua personalidade, seu modo de perceber a realidade e o funcionamento de suas estruturas cognitivas, e suas habilidades, em diferentes áreas do conhecimento. Destaca-se a metodologia utilizada para o ensino como uma das causas pelas quais os alunos têm dificuldades de aprender determinados conteúdos, pois ela é a mesma para alunos com diferentes estilos cognitivos. Não existe um estilo bom ou ruim e nem ele é estático, existem diferenças que bem trabalhadas são importantes para a interação entre $o$ aluno e o objeto de aprendizagem. Os alunos não possuem um único estilo, mas há um estilo predominante cuja dimensão vai determinar como ele aprende melhor.

A construção do conhecimento se faz por meio de uma ação interativa do sujeito com o objeto de aprendizagem, o que leva para uma ação reflexiva e para um nível crescente de aperfeiçoamento. O conhecimento é formado pela criação de esquemas mentais, que são as informações, regras, crenças e atitudes adquiridas através dos processos cognitivos. $\mathrm{O}$ conhecimento construído no processo educativo formal resulta da relação significativa entre o sujeito e o objeto ou situação a ser conhecida, em uma transformação mútua.

Conforme os autores Ontoria, Luque e Gomes (2004),

"quando se aprende algo, cria-se no cérebro uma rede neuronal, que pode ser reforçada com a repetição dessa informação ou experiência. Quando se tem 
uma experiência diferente, mas relacionada à rede original, automaticamente o cérebro reescreve o arquivo para considerar a nova entrada."

Ainda, de acordo com os mesmos autores, o processo de construção do conhecimento abrange alguns componentes no cérebro, entre eles se destacam: o neocórtex que coleta as informações e é o centro do pensamento e a amígdala cerebral que é o centro do sistema límbico, sendo a principal processadora de informações emocionais, estando ligada aos processos de aprendizagem e a sua interação com o neocórtex decide a quantidade de efeito emocional que deve conter cada pensamento. Em decorrência disto, quanto mais emoção maior a chance de que a amígdala cerebral envie as informações ao armazenamento da memória de longo prazo. Por conseguinte, de acordo com os mesmos autores, despertar emoções proporciona uma aprendizagem significativa.

Toda atividade cognitiva tem implicações afetivas e a recíproca é verdadeira, pois afetividade e cognição utilizam as mesmas vias de recepção, de registro e de expressão.

Portanto, para facilitar a aprendizagem de um conteúdo, segundo Franco (1998) é preciso considerar também as relações de afeto entre o professor e o aluno, pois, a possibilidade de sucesso na aprendizagem está diretamente vinculada à forma como o conteúdo é apresentado ao aprendiz.

Existem teorias que subsidiam práticas pedagógicas que permitem que sejam elaborados materiais educacionais que contemplem o estilo cognitivo predominante do aluno. Isso facilita a aprendizagem de novos conteúdos, ou seja, a formação dos esquemas mentais de novas situações vivenciadas pelos alunos durante o processo de construção do conhecimento, exercitando a capacidade de raciocínio, pois, a aprendizagem processa-se por meio do estabelecimento de relações entre o novo conhecimento a ser adquirido e aquele que o aluno já detém.

Os processos cognitivos que são mecanismos mentais, como a codificação, operam nas estruturas de conhecimento de uma maneira complexa, eficiente e flexível efetivando a aprendizagem significativa de um conteúdo. Na visão de Lipman, o fato de muitos alunos universitários apresentarem deficiências (dificuldade de leitura, interpretação, extrair do texto o significado do texto, pensar abstratamente, pensar criticamente, extrair os pressupostos, ter visão de totalidade,...) no seu processo formativo, decorrem da situação de não terem desenvolvido nos anos iniciais da escolaridade as habilidades de pensamento. Reforçando esta idéia os autores Ontoria, Luque e Gomes(2004).

"a infância constitui uma oportunidade crucial para a modelação das tendências emocionais que o indivíduo mostrará por toda sua vida, e os hábitos adquiridos nessa época acabam por gravar-se tão profundamente em meio à trama sináptica básica da arquitetura neuronal que depois será muito difícil serem modificados."

A aprendizagem pode ser provocada por motivação intrínseca do aprendiz, ou seja, a partir de um problema a ser resolvido o aprendiz busca vencer as barreiras que o impedem de resolver o problema entrando em uma situação de aprendizagem como meio para alcançar o fim. Ela pode ser provocada também por uma estimulação externa, ou seja, o aprendiz é induzido por motivação extrínseca, o estímulo vem de fora. Nesse caso o jogo computadorizado tem um papel significativo, pois fascina, empolga, estimula. Assim como em todas as áreas da atividade humana a Educação também deve aproveitar o que a tecnologia digital oferece para promover o processo de ensino e aprendizagem e gerar conhecimento. A área da Informática na Educação subsidia o uso do computador como recurso didático. A grande contribuição da Informática para a Educação é a possibilidade de usar o computador como um efetivo recurso didático, agregando à tecnologia digital os recursos oferecidos pela Educação e pela Psicologia.

\section{JOGOS EDUCATIVOS DIGITAIS}

Os jogos educativos digitais apresentam um conteúdo a ser aprendido e atividades práticas com objetivos educacionais baseados no lazer e diversão. São atrativos e podem ser muito 
divertidos. A motivação do aprendiz acontece como consequiência da abordagem pedagógica adotada que utiliza a exploração livre e o lúdico. Os jogos educacionais aumentam a possibilidade de aprendizagem, pois, os aprendizes se envolvem na trama do jogo, fazendo o possível para vencer determinados desafios, em consequiência, aprendem os conteúdos inseridos no jogo. Além disso, auxiliam na construção da autoconfiança e incrementam a motivação no contexto da aprendizagem.

A atividade de jogar é uma alternativa de realização pessoal que possibilita a expressão de sentimentos e de emoção. Isso, de acordo com o processo de conhecimento cerebral, oportuniza mais facilmente a aprendizagem significativa. Conforme Silveira(1999),

"os jogos computadorizados são elaborados para divertir os alunos e com isto prender sua atenção, o que auxilia no aprendizado de conceitos, conteúdos e habilidades embutidos nos jogos, pois, estimulam a auto aprendizagem, a descoberta, despertam a curiosidade, incorporam a fantasia e o desafio".

Para se utilizar um software no ambiente de ensino, este não precisa necessariamente ter sido criado para tal função, pode ser um jogo de entreter que desenvolva habilidades. Desta forma cabe ao professor utilizá-lo de maneira adequada, para auxiliar no processo de ensino e aprendizagem, oportunizando a construção do conhecimento.

Conforme os autores Figueiredo e Bittencourt(2005), "os aprendizes, de um modo geral, investem no prazer lúdico, no desafio do momento, na alegria, às vezes também, nos esforços sofridos a fim de vencer os obstáculos." O fato é que para eles, não se joga objetivando adquirir conhecimentos de uma disciplina escolar, mas o de se divertir.

Desta forma, por que não aproveitar a motivação dos alunos pelos jogos, em especial, os computadorizados, para inseri-los em um contexto no qual se aprende pelo ato de jogar?

Para a autora Falkembach (2005),

"os jogos educativos desenvolvidos com os recursos da multimídia permitem a interação, estimulam, envolvem e capturam, de maneira lúdica e prazerosa, a atenção da criança por maior intervalo de tempo. São elaborados para divertir os alunos e aumentar a chance na aprendizagem de conceitos, conteúdos e habilidades embutidos no jogo".

A concepção e elaboração de um jogo educacional deve levar em conta as informações e a interação entre o aluno e a tarefa de aprendizagem, a fim de escolher o tipo de abordagem pedagógica. Não é o meio usado que possibilita uma aprendizagem significativa, mas, a abordagem pedagógica que guia a maneira como ele é usado.

Um jogo bem projetado envolve interação, mantendo o interesse do aluno enquanto desenvolve habilidades, socializam, auxiliam na construção do conhecimento e do raciocínio. Os jogos educativos digitais se usados de forma efetiva, desempenham um papel importante para o desenvolvimento do aluno, promovendo a iniciativa pessoal e de grupo, a solidariedade, o respeito mútuo e a formação de atitudes sociais, sendo um poderoso elemento de motivação no ambiente de aprendizagem. Concordando com esta idéia, Stahl(2002) diz que:

"um jogo educativo por computador é uma atividade de aprendizagem inovadora nas quais as características do ensino apoiado em computador e as estratégias de jogo são integradas para alcançar um objetivo educacional específico".

Portanto, jogos educativos digitais usados em sala de aula podem auxiliar na aprendizagem.

\section{USO DE JOGOS DIGITAIS NA ESCOLA}

$\mathrm{O}$ uso de jogos digitais no processo de ensino e aprendizagem constitui-se em um estímulo para o desenvolvimento do aluno e faz com que ele aprenda a conviver e a valorizar o grupo social no qual está inserido. Por meio do lúdico, o aluno constrói conhecimento e torna-se um agente transformador.

Os jogos educacionais se caracterizam por estimular a imaginação infantil, auxiliar no processo de integração grupal, liberar a emoção, facilitar a aprendizagem e auxiliar na 
aquisição da auto-estima. A importância do jogo está na satisfação da necessidade da criança identificar-se com a realidade. Essas necessidades são geradas porque as crianças são entendem as regras impostas pelos adultos, como por exemplo: hora de dormir, comer, tomar banho, não mexer em certos objetos, etc.

Um aspecto negativo, que até nos dias de hoje se constata, segundo Brougére(1998). É de que o jogo ainda é julgado no ambiente escolar como uma atividade que não é dedicado à educação, mas ao descanso e lazer antes do retorno ao trabalho. Conforme este autor, a participação em jogos contribui para a formação de atitudes sociais como, respeito mútuo, cooperação, respeito às regras, senso de responsabilidade e de justiça, iniciativa pessoal e em grupo.

Os jogos, segundo Passerino(2002),

podem ainda apresentar alguns benefícios indiretos, como o desenvolvimento: da memória visual, auditiva, cinestésica; da coordenação motora ampla e fina; proporcionar orientação temporal e espacial, em duas e três dimensões; percepção auditiva e visual de tamanho, cor, detalhes, forma, posição, lateralidade; desenvolvimento do raciocínio lógico-matemático, bem como da expressão lingüística oral e escrita, trabalhando planejamento e organização.

De acordo com o autor Vygotsky(1989), os jogos propiciam o desenvolvimento da linguagem, do pensamento e da concentração. O lúdico influencia no desenvolvimento do aluno, ensinando-o a agir corretamente em uma determinada situação e estimulando sua capacidade de discernimento. Os jogos educacionais são uma alternativa de ensino e aprendizagem e ganham popularidade nas escolas. Sua utilização deve ser adequada pelos professores como um valioso incentivador para a aprendizagem, estimulando as relações cognitivas como o desenvolvimento da inteligência, as relações afetivas, verbais, psicomotoras e sociais. Os jogos provocam uma reação ativa, crítica e criativa nos alunos, socializando o conhecimento. O educando é diferenciado e valorizado como pessoa. Os aspectos afetivos são determinantes na construção da personalidade e eles se revelam de forma explícita no jogo.

Conforme Antunes(1998),

“os jogos devem ser utilizados somente quando a programação possibilitar e somente quando se constituírem em um auxílio eficiente ao alcance de um objetivo dentro dessa programação".

O papel do professor é de saber a hora certa de usar os jogos, eles não podem ser utilizados quando os alunos não estão dispostos e entusiasmados para isso, pois se torna improdutivo e cansativo, o que leva ao desprazer de jogar, enquanto que o propósito é exatamente o oposto disso. Os jogos que possuem desafios são excelentes, pelo fato de exigir um raciocínio mais elaborado, mas se os alunos não tiverem maturidade para tais jogos, é necessário que usem outros até conseguir atingir o nível suficiente para inserir os desafios. No projeto relacionado a esse artigo as atividades digitais / jogos são para a pré-escola e foram criadas a partir da fundamentação teórica, modeladas e foram implementadas as atividades digitais que têm por objetivo o desenvolvimento da coordenação motora, da percepção visual, classificação, seriação, concentração e noção de formas geométricas planas: quadrado; retângulo; triângulo e círculo. As atividades englobam tamanho, forma, cor e espessura das figuras geométricas, estabelece a relação de dimensões entre as formas, a identificação da forma geométrica, das cores e da espessura, além de melhorar o raciocínio abstrato o que possibilita a construção do conhecimento e não apenas a memorização e a reprodução de técnicas.

Os jogos educacionais, incluindo os digitais, de fato, estimulam o desenvolvimento cognitivo, auxiliando na criação de estratégias para a solução de problemas. Passada a fase inicial da brincadeira, o aluno demonstra pouco a pouco uma perspectiva bastante individual de atingir o objetivo proposto e isso implica em ganhos cognitivos que ocorrem de forma gradativa. 
Os jogos podem explorar diversos aspectos. Os jogos de exercício, simbólicos e de construção exploram a ludicidade. Os jogos que exigem o raciocínio prático, a discriminação e a associação de idéias proporcionam a aquisição de condutas cognitivas. Os jogos que exploram a aplicação de regras, a localização, a destreza, a rapidez, a força e a concentração auxiliam no desenvolvimento de habilidades funcionais. Os jogos que ajudam a desenvolver a confiança, a autonomia e a iniciativa propiciam a aquisição de condutas afetivas. Considerando que a repetição é uma condição básica para a aprendizagem o projeto de um jogo deve prever a motivação para que o aluno retorne ao jogo várias vezes. Jogos muito fáceis ou usados de forma ineficaz são descartados rapidamente. Para atrair o aluno o jogo deve ser lúdico, ou seja, deve ensinar e divertir ao mesmo tempo incorporando a diversão para estimular a aprendizagem de conteúdos e habilidades através do entretenimento.

Utilizar o lúdico é um recurso interessante que atende o pensamento do autor Macedo, Petty e Passoa (2005) quando afirma que:

"Escola obrigatória que não é lúdica não segura os alunos, pois eles não sabem nem têm recursos cognitivos para, em sua perspectiva, pensar na escola como algo que lhes será bom em um futuro remoto, aplicada a profissões que eles nem sabem o que significam."

Os PCNs (Parâmetros Curriculares Nacionais) orientam a atualização e qualificação do ensino para preparar cidadãos autônomos, críticos, criativos e reflexivos para o mundo contemporâneo, situam-se em princípios construtivistas, em que o professor e a escola propiciam a construção de habilidades e conhecimento aos alunos. Para que essas orientações se realizem é essencial, conforme Antunes(1998):

"a interação do sujeito com o objeto a ser conhecido e, assim, à multiplicidade na proposta de jogos concretiza e materializa essas interações".

Desta forma, os jogos são ferramentas valiosas para aprendizagem. Neste sentido o jogo computadorizado, ou seja, o jogo digital é uma modalidade que se presta muito para este processo, uma vez que os alunos, na sua maioria, utilizam o computador como entretenimento (jogos, Internet, desenhos) e, muitas vezes ocupam a maior parte de seu dia nos computadores do que em outras atividades. Por conseguinte, utilizar os jogos educativos digitais, como instrumento mediador do processo de ensino e aprendizagem torna-se importante, pois os alunos encontram significado para sua aprendizagem, eles se envolvem emocionalmente com os jogos. Os professores podem dispor de jogos educativos digitais via Internet ou por meio dos objetos educacionais disponíveis como recurso didático. Para facilitar ainda mais o processo de ensino e aprendizagem do conteúdo foi incluído na aplicação um agente pedagógico.

\section{O AGENTE PEDAGÓGICO}

Segundo Silveira(2005), um Agente Pedagógico é um recurso que permite acrescentar em um sistema hipermídia mecanismos que interpreta as percepções do aluno, estabelece inferências, resolve problemas e determina ações, ou seja, atua sobre o ambiente/sistema para realizar um conjunto de tarefas para as quais foi programado. Os Agentes Pedagógicos estão trazendo uma nova perspectiva aos ambientes de aprendizagem e às aplicações educativas digitais adaptando as interações às necessidades dos alunos, ajudando-os a superar suas dificuldades de aprendizagem. Os agentes devem exibir um comportamento coerente respondendo às interações do aluno com a aplicação.

\section{A APLICAÇÃ̃O}

A aplicação foi modelada e suas atividades implementadas usando um Sistema de Autoria. Dentre as atividades estão as de identificação da forma geométrica, das cores, do tamanho e da espessura e a identificação de certas características. A tela de apresentação exibe os agentes que o aluno pode escolher para acompanhá-lo nas atividades: 


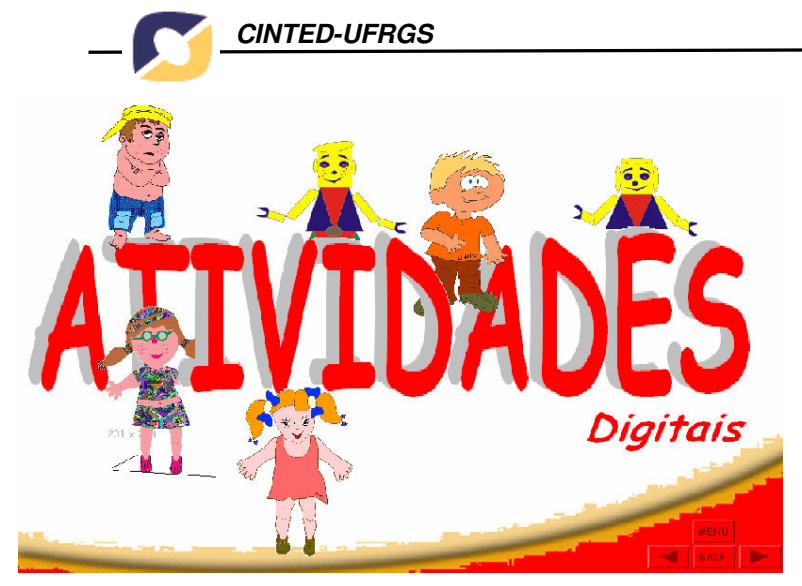

Figura 1 - Tela de apresentação Figura

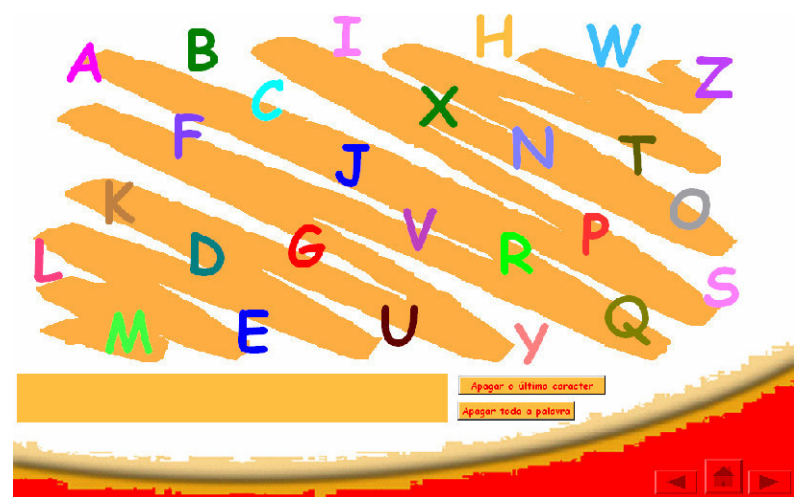

2 - Tela de identificação

A aplicação solicita a identificação do aluno para estabelecer a interação alunoagente(figura 2). As atividades desenvolvidas são:

a) Atividades para identificar as formas, exibem as formas geométricas e solicitam aos alunos para clicar sobre determinada figura;

b) $\mathrm{Na}$ atividade representada na figura 3 é solicitado que a criança pinte figura com uma determinada cor;

c) Atividades nas quais o aluno precisa distinguir além da forma se as figuras são finas ou grossas, pequenas ou grandes (Figura 4);

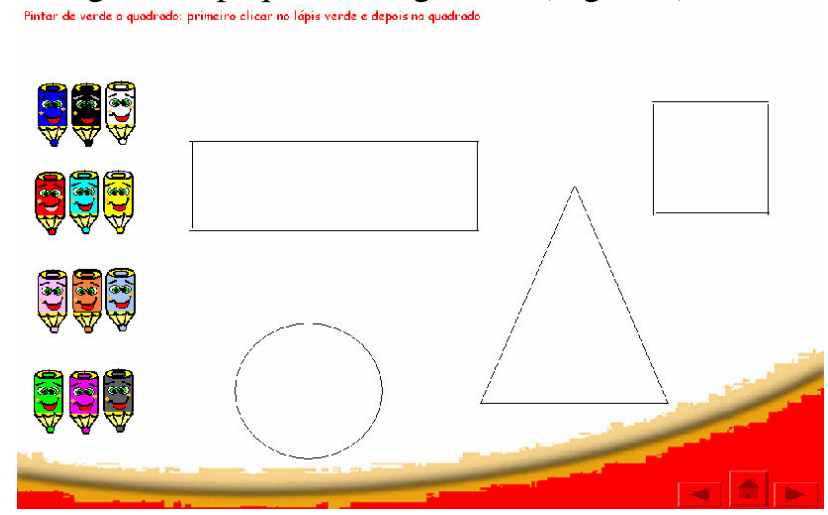

Figura 3 - Tela para colorir as figuras Figura

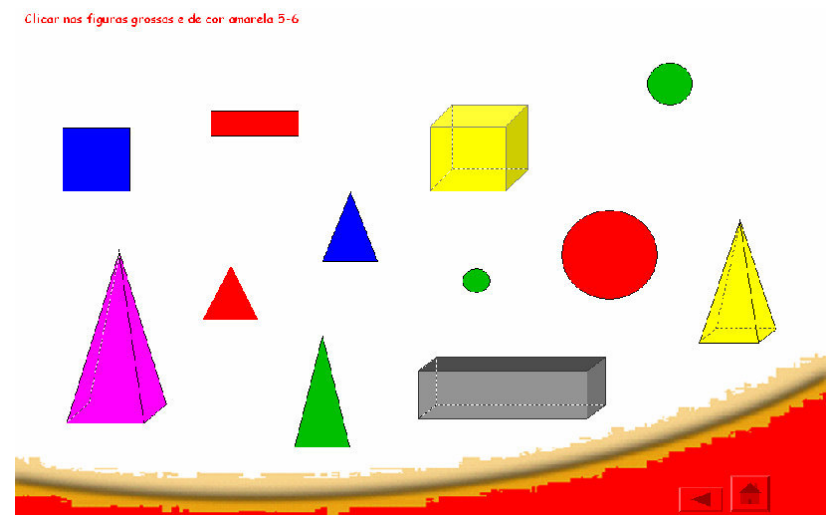

4 -Tela para reconhecer espessura

d) Atividades em que a criança precisa reconhecer o tamanho e fazer corresponder com a cor das bolas;

e) Atividades exigem que o aluno reconheça na figura ao lado as formas correspondentes às figuras da esquerda (Figura 5). 


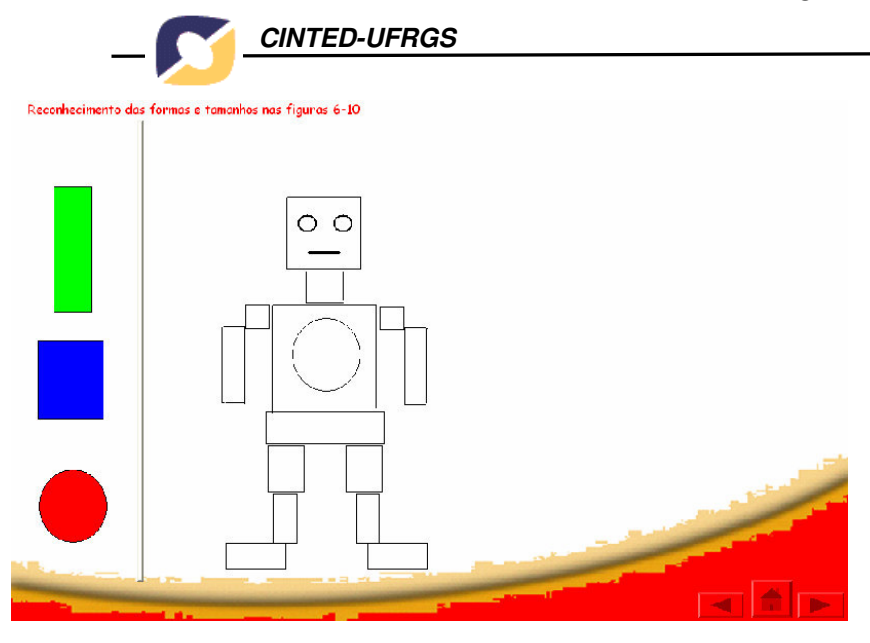

Figura 5 - Tela reconhecer as formas Figura

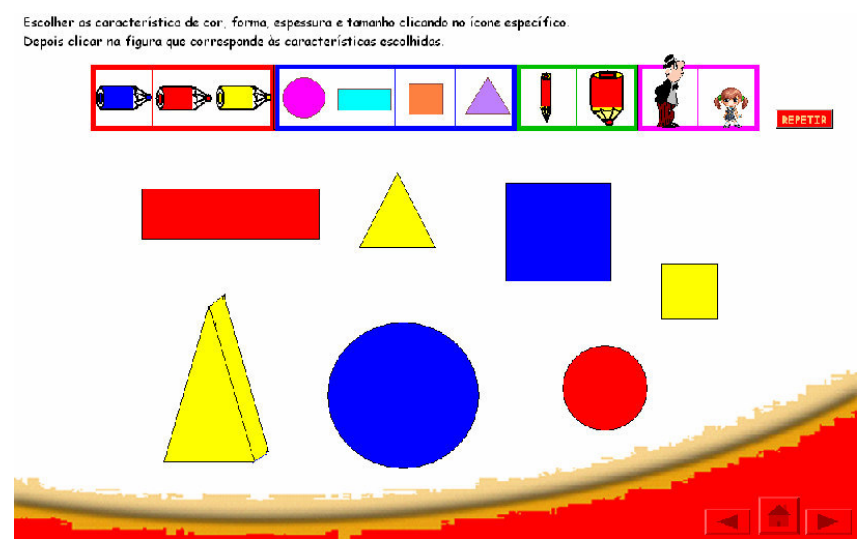

6 -Tela reconhecer características

f) Outro tipo de atividade faz com que a criança tenha que reconhecer as características de forma e cor e arrastar a figura correspondente até os quadros;

g) Atividade que movimenta as bolas nas cores, azul e vermelho, e a criança precisa arrastála para o recipiente correspondente à cor (reconhecimento de cor);

h) Atividade que permite que a criança escolha segundo sua vontade, a cor, a forma, o tamanho, a espessura ao terminar a escolha são mostradas diversas figuras e ela precisa reconhecer a figura correspondente às características escolhidas (Figura 6).

Durante o uso das atividades a criança conta com o agente pedagógico que a acompanha interferindo quando necessário para auxiliá-lo ou para dar-lhe um feedback positivo caso tenha acertado.

\section{CONCLUSÕES}

Utilizar novos recursos didáticos é fundamental, uma vez que, os alunos não estão mais satisfeitos com quadro e giz, também neste contexto tradicional de educação a aprendizagem dos alunos está deixando a desejar. Destacar o lúdico como uma maneira de contribuir para motivar os alunos a buscar, pesquisar, construírem o conhecimento, trabalharem de forma cooperativa, seria uma forma de ter o educando na escola, não por obrigação, mas por vontade de aprender.

Os jogos de um modo geral desenvolvem capacidades, conhecimentos, atitudes e habilidades, entre eles, destaca-se que: favorece a mobilidade, a imaginação, a diversão, a aceitação de regras, o desenvolvimento do raciocínio lógico e comum, entre outros.

Desta forma, utilizar os jogos, em especial os jogos educativos digitais, é extremamente relevante, pois, os alunos se identificam e se envolvem emocionalmente, propiciando uma aprendizagem significativa, principalmente na disciplina de Matemática, que na maioria das vezes, os alunos sentem extrema dificuldade.

O uso das tecnologias digitais na Educação é inquestionável. Portanto, através dos recursos oferecidos pelas tecnologias digitais é possível planejar, desenvolver e analisar atividades lúdicas, integrando profissionais da área técnica com os da área pedagógica para criar jogos educativos digitais. Incorporar os jogos na Educação pode oferecer um universo complexo de significados, centrado no lúdico, subsidiando a construção do conhecimento do aluno conforme seu ritmo, de forma agradável, agregando entretenimento, informação e ludicidade e preparando-o para ser um cidadão na Sociedade do Conhecimento.

\section{REFERENCIAS}

ANTUNES, Celso. Jogos para estimulação das múltiplas inteligências. Vozes, Petrópolis, 1998.

BATLORI, Jorge;. Jogos para treinar o cérebro. Madras, São Paulo, 2004.

BORDENAVE, J.D.Estratégias de Ensino - Aprendizagem. Vozes, Petrópolis, 1996. BROUGÉRE,G. Jogo e educação. Artes Médicas, Porto Alegre, 1998. 
$-\Gamma$

FABRE, M. C. J. M.; TAROUCO, L. M. R.; TAMUSIUNAS, F. R. Reusabilidade de objetos educacionais. RENOTE -. Porto Alegre: CINTED-UFRGS, v. 1, n. 1, 2003.

FIGUEIREDO, C., BITTENCOURT, J.. Jogos Computadorizados para Aprendizagem Matemática no Ensino Fundamental: Refletindo a partir dos Interesses dos Educandos - RENOTE: Vol. 3 n $^{\circ} 1$ - CINTED - UFRGS, 2005.

FALKEMBACH, G.A.M. Informática na Educação: Novos paradigmas - I Congresso Nacional de Escolas Franciscanas Santa Maria -2000

FALKEMBACH, G.A.M. Concepção e desenvolvimento de material educativo digital Revista Novas Tecnologias na Educação - CINTED - UFRGS, 2005.

MACEDO, L; PETTY, A.L. S; PASSOS, N. C. Os Jogos e o Lúdico na aprendizagem escolar. Artmed, Porto Alegre. 2005.

ONTORIA PENÃ, A; LUQUE, A; GÓMES, J.P.;. Aprender com Mapas Mentais. Madras, São Paulo. 2004.

PASSERINO, L. 2002. Avaliação de jogos educativos computadorizados. Disponível em: <http://www.c5.cl/ieinvestiga/actas/tise $98 / \mathrm{html} /$ trabajos/jogosed/>.

SILVEIRA, S.R. - Estudo e Construção de uma ferramenta de autoria multimídia para a elaboração de jogos educativos. Dissertação POA-PPGC UFRGS 99

STAHL, Marimar M. Ambientes de ensino-aprendizagem computadorizados: da sala de aula convencional ao mundo da fantasia. Artmed, Porto Alegre. 2002

VYGOTSKY, LS. A formação social da mente. Martins Fontes. São Paulo, 1989

FRANCO, S.R.K. O Construtivismo e a Educação. Porto Alegre: Mediação, 1998

SILVEIRA, S.R. Formação de grupos colaborativos em um ambiente multiagente interativo de aprendizagem na Internet: um estudo de casos utilizando sistemas multiagentes e algoritmos genéticos - tese de doutorado - Porto Alegre: PGIE/UFRGS, 2005. Tese de Doutorado em Informática. 